\title{
Incidental Non-cardiac Findings in Cardiovascular Imaging
}

\author{
Mark T. Macmillan ${ }^{1}$ \\ Michelle C. Williams ${ }^{2,3, *}$
}

\author{
Address \\ ${ }^{1}$ Department of Radiology, Royal Infirmary of Edinburgh, Edinburgh, UK \\ *,2University of Edinburgh/BHF Centre for Cardiovascular Science, Chancellor's \\ Building, SU305, 49 Little France Crescent, Edinburgh, EH16SUF, UK \\ Email: michelle.williams@ed.ac.uk \\ ${ }^{3}$ Edinburgh Imaging facility QMRI, University of Edinburgh, Edinburgh, UK
}

Published online: 23 0ctober 2018

(C) The Author(s) 2018

This article is part of the Topical Collection on Imaging

Keywords Imaging $\cdot$ Incidental non-cardiac findings $\cdot$ Cardiac imaging

\section{Abstract}

Improvements in imaging techniques have led to an expansion in the number of crosssectional cardiac studies being performed. This means that incidental non-cardiac findings (INCF) identified on cardiac imaging have become an important clinical concern. The majority of INCF are not clinically significant. However, some INCF will require follow-up or changes in management. Differentiating clinically significant from non-significant INCF can be challenging, particularly given the breadth of potential findings and the range of organ systems involved. Following up INCF also has economic implications. Recent changes to the lung nodule follow-up guidelines will reduce the cost of following up incidental lung nodules. In this manuscript, we discuss the common and important INCF which may be identified in cardiovascular imaging and explore potential implications of these findings.

\section{Introduction}

Technological advances have allowed the development of computed tomography (CT), magnetic resonance imaging (MRI) and nuclear imaging methods to assess the heart and coronary arteries. However, the increasing use of cross sectional imaging has also led to increased detection of incidental non-cardiac findings (INCF).
These findings can affect any organ in the imaged fieldof-view, with lung abnormalities being the most common. The identification of INCF is important in cardiac imaging in order to identify alternative causes of symptoms or previously undiagnosed conditions that require investigation or treatment. The detection of INCF may 
also have important implications for patients and may necessitate additional imaging, consultations, follow-up or treatment.

\section{Frequency of INCF}

INCF can be defined as abnormalities which are potentially clinically relevant and are identified despite being unrelated to the purpose of the investigation [1]. They can be classified as benign or clinically significant, with clinically significant findings being those which cause symptoms or require further investigation or management [2•]. In the context of cardiac CT it is often difficult to strictly differentiate between INCF which are truly incidental and those that may be the cause of the patient's symptoms of chest pain or breathlessness. This is one reason for differences in the prevalence of INCF between studies.

INCF are frequent in all forms of cardiac imaging; in cardiac CT, approximately $44 \%$ of patients will have at least one non-cardiac finding [3••], in cardiac MRI 35\% [4] and in cardiac SPECT 55\% [5]. The rate of clinically significant INCF is between 10 and $17 \%[2 \bullet, 3 \bullet \bullet, 6-8$, $9 \bullet \bullet, 10]$. In a meta-analysis of 11,703 patients in 13 studies, acutely life-threatening INCF were identified on CT in $2.2 \%$ and malignancy was identified in $0.3 \%$ $[9 \bullet \bullet]$. In a meta-analysis of 5082 patients in 10 studies, the frequency of malignancy on CT was estimated as $0.7 \%[3 \bullet \bullet$. Similar rates of malignancy have been identified in the low-dose CT performed for attenuation correction in SPECT imaging [11].

The type of imaging performed impacts the prevalence of INCF as they are least common in non-contrast CT for calcium scoring and more common in CT performed to assess bypass grafts or pulmonary veins [12]. In nuclear imaging, INCF may be identified where the abnormality causes an increase or decrease in the normal uptake, particularly in organs involved in tracer excretion. If cross-sectional vascular imaging is performed prior to structural interventions such as transcutaneous aortic valve implantation (TAVI), then more INCF will be identified due to the larger scan range and potentially older population. The frequency of clinically significant INCF in pre-TAVI patients is 17 to $18 \%$ [13, 14]. One study found that the identification of INCF in these patients is associated with a lower chance of TAVI being performed and a worse overall outcome [15]. However, other studies have found that after multivariate analysis, outcomes after TAVI were not influenced by
INCF [14] and that 2 year outcomes were similar after a decision to perform the TAVI was made [16].

In addition to this substantial prevalence, INCF can be identified within any organ within the imaged fieldof-view. Nevertheless, imaging optimised for cardiac assessment may not be optimal for assessing other organs and thus may under- or overestimate the presence of abnormalities in other organs. Therefore, a diverse range of INCF are possible, and a wide breadth of knowledge is required to read these examinations and recommend suitable subsequent investigations or follow-up for INCF.

\section{Lungs}

The lungs are the most common site for INCF on cardiac imaging, largely due to the prevalence of pulmonary nodules and emphysema (Table 1, Fig. 1) [6, 7]. Lung nodules occur in $14 \%$ of patients undergoing coronary CT angiography [17]. Many of these require no further investigation or treatment, but some may represent important treatable malignancy or require further followup imaging.

In cardiac CT, the lungs should be assessed on both scout images and wide field-of-view images reconstructed with a dedicated lung reconstruction algorithm. Cardiac CT images usually cover only the lower chest in order to minimise radiation dose, so abnormalities in the upper zones may only be visible on scout images. More INCF will be identified on wide field-of-view imaging, as $54 \%$ of the total lung volume is visualised

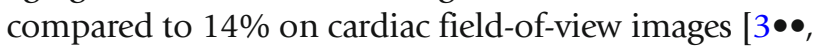
18 ]. Indeed, $80 \%$ of pulmonary nodules seen on the wide field-of-view images are not seen on the limited cardiac field-of-view [19].

Similar abnormalities may be identified on the CT performed for attenuation during SPECT or PET imaging. Some malignancies may also take up radiotracers during SPECT imaging, such as carcinoid tumours [20, 21]. During cardiac MRI, lung abnormalities may be identified on any sequences, but in particular, axial and coronal images should be reviewed for the presence of INCF. One study found that INCF were easier to identify on balanced steady state free precession (bSSF) images but that T1w-half-fourier acquisition single-shot turbo spin-echo (HASTE) could provide additional diagnostic information [22].

Pulmonary nodules represent a challenge in cardiac imaging as, although many are benign, it is important to identify nodules with a risk of malignancy and organise suitable follow-up. Guidelines for the follow-up of lung 


\section{Table 1. Common INCF identified on cardiovascular imaging}

\begin{tabular}{|c|c|c|}
\hline Organ & Finding & \\
\hline \multirow[t]{4}{*}{ Lung } & Lung nodules & $\begin{array}{l}\text { Benign nodules, intrapulmonary lymph nodes, calcified granulomata, malignant } \\
\text { nodules or masses }\end{array}$ \\
\hline & $\begin{array}{l}\text { Parenchymal } \\
\text { abnormalities }\end{array}$ & Emphysema, pulmonary fibrosis bronchiectasis \\
\hline & Infections & Bacterial pneumonia, tuberculosis, atypical infections \\
\hline & Pleural abnormalities & Pleural effusion, pleural plaques, pleural malignancy \\
\hline \multirow[t]{3}{*}{ Mediastinum } & Lymphadenopathy & \\
\hline & Mediastinal mass & Thymoma, teratoma, lymphoma, germ cell malignancy, benign cyst \\
\hline & Thoracic aorta & Atherosclerosis, aneurysm, dissection \\
\hline Neck & $\begin{array}{l}\text { Thyroid } \\
\text { Lymphadenopathy }\end{array}$ & Cyst, nodule, malignancy \\
\hline \multirow[t]{9}{*}{ Abdomen } & Liver & Cyst, haemangioma, malignancy, fatty infiltration, cirrhosis, ascites \\
\hline & Gallbladder & Calculi, cholecystitis, malignancy \\
\hline & Kidneys & Cyst, malignancy, calculi, scarring \\
\hline & Pancreas & Calcification, cyst, malignancy, atrophy \\
\hline & Spleen & Enlargement, cyst, malignancy \\
\hline & Stomach & Malignancy \\
\hline & Large and small bowel & Malignancy, diverticulosis, hernia \\
\hline & Adrenals & Benign adenoma, metastasis, primary malignancy \\
\hline & Pelvic organs & Uterus, ovary, prostate, testes, bladder \\
\hline \multirow[t]{3}{*}{ Bones } & Benign lesion & Haemangioma, bone island \\
\hline & Malignant lesion & Metastasis, primary malignancy \\
\hline & Degenerative lesion & Osteoarthritis, compression fracture \\
\hline
\end{tabular}

nodules have recently been updated with the 2017 Fleischner society guidelines [23] and the 2015 British Thoracic Society guidelines [24]. The 2005 Fleischner guidelines recommended routine follow-up imaging for nodules greater than 4-mm diameter with the interval determined by nodule size, characteristics and clinical risk factors [25]. This lead to a significant burden of follow-up imaging after cardiac CT [2•]. The revised 2017 Fleischner guidelines increase the threshold for follow-up imaging to $6 \mathrm{~mm}$ or $100 \mathrm{~mm}^{3}$ [23]. Part-solid or "ground glass" nodules require follow-up for longer due to the risk of in situ and low-grade adenocarcinoma [26].

Whilst the majority of pulmonary nodules are found to be clinically insignificant, there is a subgroup which represent malignant disease. The prevalence of malignancy in patients undergoing cardiac CT is estimated at
$0.7 \%$, and $72 \%$ of these are attributed to lung cancer $[3 \bullet \bullet$. In comparison, the baseline prevalence of lung cancer was $1 \%$ in the National Lung Screening Trial (NLST) [27] and 1.7\% in the UK Lung Cancer Screening (ULCS) pilot trial [28]. The NLST compared the use of low-dose CT and chest radiographs and demonstrated a $20 \%$ relative reduction in mortality in the CT group [29]. The ULCS pilot trial demonstrated that it was possible to detect lung cancer earlier and provide curative therapy in $80 \%$ of cases [28]. Considering the small difference in prevalence between cardiac CT studies and those selected for lung cancer screening, it is not unreasonable to postulate that detection and follow-up of pulmonary nodules detected by cardiac CT may similarly reduce mortality.

INCF which require acute intervention may also be identified in the lungs, particularly on contrast- 


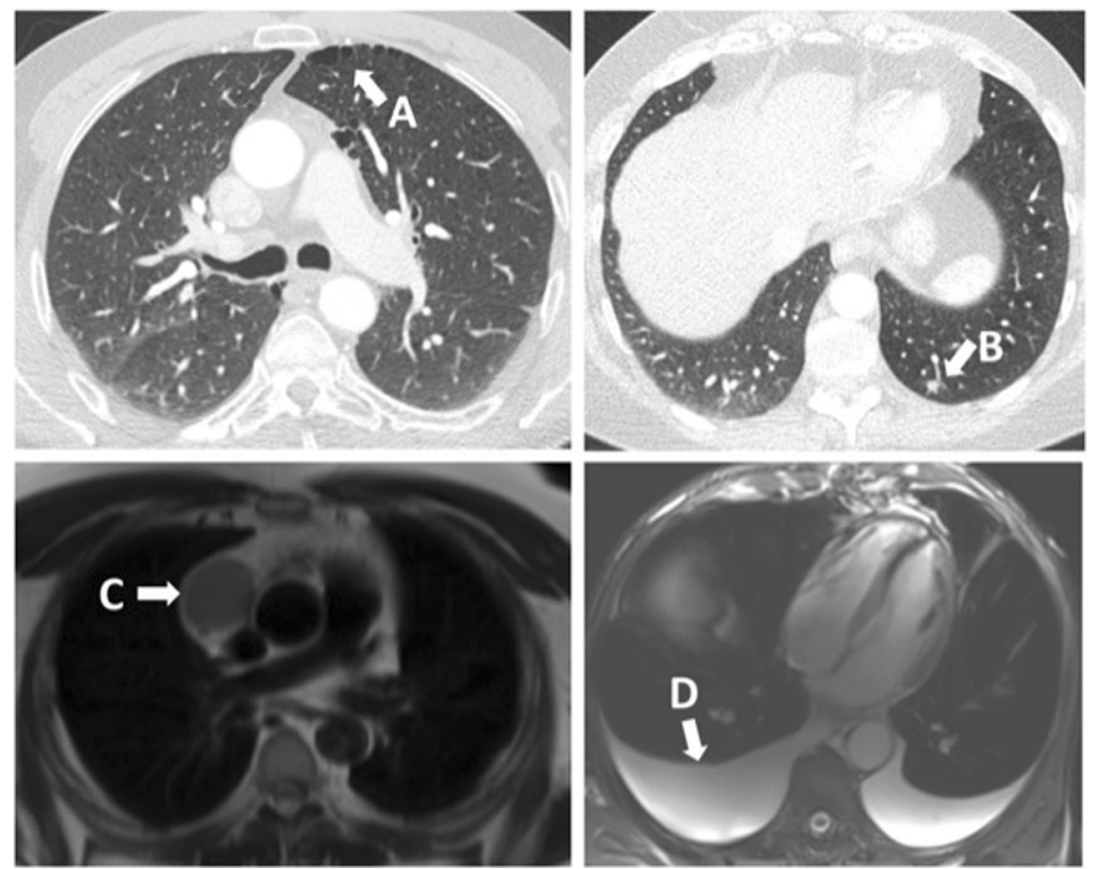

Fig. 1. CT and MRI images of common INCF ( $A$, paraseptal emphysema on CT; B, 7-mm pulmonary nodule on CT which requires follow-up imaging; $C$, mediastinal lymphadenopathy on MRI; D, pleural effusion on MRI).

enhanced cardiac CT. The pulmonary arteries are often opacified to some degree during cardiac CT, which allows for detection of pulmonary embolism. Analysis of incidental findings in the SCOT-HEART study identified pulmonary embolism in $0.2 \%$ of patients ${ }^{6}$. Whilst this is a relatively low proportion, the morbidity and mortality associated with pulmonary embolism are significant. Similarly, pneumonia, including atypical infections, is a treatable condition which may be identified on cardiac imaging.

Cardiac imaging may also identify previously unknown chronic lung conditions such as emphysema or pulmonary fibrosis. There is an overlap between COPD and coronary artery disease in terms of risk factors such as smoking and pathological mechanisms such as inflammation [30]. Therefore, the frequent identification of emphysema on cardiac CT is not unexpected. Depending on the phase of respiration and use of iodinated contrast, it may not be possible to identify subtle parenchymal abnormalities, as these may be obscured on images obtained in expiration or with contrast. The identification of pulmonary fibrosis can be challenging on cardiac CT performed with contrast enhancement, and subsequent non-contrast CT imaging may be required to assess the lung parenchyma. Subtle changes of lung parenchymal abnormalities may also be identified on raw SPECT images, such as the flattening of the diaphragm in patients with COPD or reduced counts in patients with pleural effusions [20].

\section{Mediastinum}

Enlarged mediastinal lymph nodes are a common INCF in both cardiac MRI and CT, and may be identified in 2.4 to $4.7 \%$ of patients undergoing MRI $[6,31]$ and $1.7 \%$ of patients undergoing cardiac CT [2•]. These lymph nodes can indicate underlying malignancy or inflammation, and therefore are essential to detect and interpret. In general, mediastinal lymph nodes which are greater than $10 \mathrm{~mm}$ in the shortest axial diameter are considered abnormal. However, nuances exist within different nodal stations [32] as normal subcarinal lymph nodes may measure up to $2 \mathrm{~cm}$ and normal right lower paratracheal nodes can measure up to $1.5 \mathrm{~cm}$ [33]. Conversely retro-crural and epicardial lymph nodes may be abnormal at much smaller diameters [34]. Mediastinal masses may also be identified during cardiac imaging. These may represent benign pericardial, bronchogenic or oesophageal duplication cysts. However, 
malignant pathologies such as teratoma, thymoma, thyroid malignancy, germ cell tumours and lymphoma can also be identified.

Depending on the portion of the chest imaged, the ascending, arch and descending thoracic aorta may be visible on cardiac imaging. A discussion of the significance of incidental aortic atherosclerosis is out with the scope of this article but may represent a clinically important finding and is associated with prognosis [35]. Incidental thoracic aortic aneurysms can be identified on CT or MRI imaging, as are vascular anomalies which could be important for subsequent invasive investigations. Intramural haematoma may be identified as high attenuation within the wall of the aorta on non-contrast CT imaging. Aortic dissection is a potentially lethal INCF which may be identified in patients with acute chest pain. In a study of over 11,000 patients undergoing cardiac CT for acute chest pain, $1.1 \%$ has an aortic dissection [36].

Hiatus hernia is a very common INCF which may be identified on cardiac CT and MRI. Although this may be an alternate cause for the patient's symptoms, they may also be asymptomatic. In our centre, the identification of hiatus hernia on cardiac CT was not associated with the instigation of gastric acid suppression therapy [2•]. The oesophagus is difficult to assess on cardiac CT, but oesophageal masses may be identified and endoscopy would be required to assess these further.

\section{Neck}

The lower neck is often included as part of localising images on cardiac MRI or the scout images performed during cardiac CT. The most common pathologies identified are thyroid nodules and lymph node enlargement. Lymph nodes may also be identified in the supraclavicular fossa on MRI or if particularly large on the scout images performed prior to cardiac CT. Similar to lymph nodes in the thorax, nodules less than $1 \mathrm{~cm}$ diameter can be dismissed in the majority of cases.

Thyroid enlargement and thyroid nodules are frequently encountered when reading cardiac MRI examinations [37]. The American Society of Thyroid Disease strongly recommends clinical history and examination, thyroid stimulating hormone (TSH) blood test and ultrasound for all cases of thyroid nodule enlargement [38]. In cases with low TSH, a nuclear imaging study of the thyroid is also recommended [38]. In theory, thyroid nodules should generate a significant burden of imaging and clinical follow-up, but in practice, this is not apparent. Grady et al. demonstrated variability in the practice of reporting thyroid nodules, even in cases of nodules greater than $20 \mathrm{~mm}$ in diameter [39]. A conservative approach is often appropriate when assessing thyroid nodules, and local guidelines should be followed.

\section{Abdomen}

Sections of the liver, spleen, pancreas, adrenals, kidneys, stomach and bowel may be imaged on cardiac CT and MI. These findings make up a significant portion of INCF, and many require no further follow-up or treatment. In cardiac CT and MRI, only a small proportion of the upper abdomen is imaged. However, in CT assessment prior to TAVI, the larger scan range will include the whole of the abdomen and pelvis.

The commonest intra-abdominal INCF are hepatic cysts, accounting for 5\% INCF [2•]. Simple hepatic cysts, which have uniform fluid attenuation, no visible wall and no contrast enhancement, are benign and require no further imaging. In cases where the cysts do not clearly meet these criteria, further assessment with ultrasound or MRI may be required. Other benign liver abnormalities that can be identified include haemangioma and fatty infiltration [2•]. Malignancy including metastases or primary malignancy may also be identified. Subtle abnormalities may be identified in the liver during SPECT imaging such as reduced radiotracer uptake in patients with cirrhosis, multiple liver cysts or malignancy [20].

The kidneys are often not fully imaged on cardiac imaging, but the upper poles are usually included on MRI and may be identified on cardiac CT. Renal cysts are a common finding and are frequently benign and require no further imaging. However, features such as septations, internal density, enhancement, calcification or solid components increase the chance of malignancy [40]. Renal cysts are classified according to the Bosniak criteria and should be followed up accordingly [41].

Adrenal, splenic and pancreatic lesions are less frequently identified but require diligent assessment, as all three organs are potential sites for malignant pathology. Adrenal nodules often represent benign adenoma, and an attenuation below 10 Hounsfield units on noncontrast imaging has a good diagnostic accuracy for identifying benign adenoma. Review of previous 
Table 2. Fleischner society guidelines for the follow-up of lung nodules ( $m$ months)

\begin{tabular}{|c|c|c|c|c|}
\hline \multirow[t]{2}{*}{ Type } & \multirow[t]{2}{*}{ Number } & \multirow[t]{2}{*}{ Size } & \multicolumn{2}{|l|}{ Follow-up CT } \\
\hline & & & Low-risk patient & High-risk patient \\
\hline \multirow[t]{6}{*}{ Solid } & Single & $<6 \mathrm{~mm},<100 \mathrm{~mm}^{3}$ & None & (Optional $12 \mathrm{~m}$ ) \\
\hline & & $6-8 \mathrm{~mm}, 100-250 \mathrm{~mm}^{3}$ & 6-12 m (consider 18-24 m) & $6-12 \mathrm{~m}$ then $18-24 \mathrm{~m}$ \\
\hline & & $>8 \mathrm{~mm},>250 \mathrm{~mm}^{3}$ & \multicolumn{2}{|c|}{$\mathrm{CT}$ at 3 months or PET/CT or biopsy } \\
\hline & Multiple & $<6 \mathrm{~mm},<100 \mathrm{~mm}^{3}$ & None & (Optional 12 m) \\
\hline & & $6-8 \mathrm{~mm}, 100-250 \mathrm{~mm}^{3}$ & 3-6 m (consider 18-24 m) & $3-6 \mathrm{~m}$ then $18-24 \mathrm{~m}$ \\
\hline & & $>8 \mathrm{~mm},>250 \mathrm{~mm}^{3}$ & 3-6 m (consider $18-24 \mathrm{~m})$ & $3-6 \mathrm{~m}$ then $18-24 \mathrm{~m}$ \\
\hline \multirow[t]{6}{*}{ Sub-solid } & Groundglass & $<6 \mathrm{~mm}$ & \multicolumn{2}{|l|}{ None } \\
\hline & & $>6 \mathrm{~mm}$ & \multicolumn{2}{|l|}{$6-12 \mathrm{~m}$ then $3-5$ years } \\
\hline & Part-solid & $<6 \mathrm{~mm}$ & \multicolumn{2}{|l|}{ None } \\
\hline & & $>6 \mathrm{~mm}$ & \multicolumn{2}{|c|}{$3-6 \mathrm{~m}$ then annually for 5 years } \\
\hline & Multiple & $<6 \mathrm{~mm}$ & \multicolumn{2}{|c|}{$3-6 \mathrm{~m}$ then at 2 years and 4 years } \\
\hline & & $>6 \mathrm{~mm}$ & \multicolumn{2}{|c|}{ 3-6 $\mathrm{m}$ then based on most suspicious nodule } \\
\hline
\end{tabular}

imaging may also help to identify clearly benign lesions. However, if these criteria cannot be fulfilled, further assessment with MRI or contrast enhanced CT may be required. Similarly, some pancreatic cysts can be clearly identified as benign, but further assessment or follow-up will be required if malignancy is suspected [42]. Splenic lesions are rare, but an enlarged spleen may be indicative of underlying pathologies, including haematological malignancy.

A limited proportion of the stomach and large or small bowel may be included on cardiac CT or MRI. The unprepared bowel can be difficult to assess, but these areas should be reviewed for incidental malignancy. Abnormal lymph nodes may be identified throughout the abdomen and pelvis. If the pelvis is imaged then assessment of the uterus, ovaries and adnexa is required and may identify incidental ovarian cysts or endometrial or ovarian malignancy. If these are suspected, then dedicated imaging of these regions will be required. Incidental inguinal hernia are a common INCF in the pelvis, particularly in elderly males.

\section{Bones and soft tissues}

The most important distinction to make when assessing lesions within the bones is whether the lesion can confidently be called benign. Fortunately, some of the more common bone lesions have classic imaging characteristics which allow them to be identified. Haemangioma have a thinned trabecular pattern on CT and on MRI are most often high signal on both T1 and T2-weighted imaging. Bone islands are uniformly dense with regular margins on CT. Irregular lesion margins, wide transitional zones and bony destruction are all features that may suggest an aggressive lesion which requires further assessment.

In older patients, degenerative change and compression fractures may be identified in the thoracic spine. These may be most apparent on sagittal images. Although they may be asymptomatic, the identification of these findings may aid future management, including identifying patients who could benefit from bone protection therapy ${ }^{26}$.

Metastases represent the most common malignant bone lesions, and these may be identified in the vertebrae, ribs, sternum, scapulae or clavicles on cardiac imaging. Careful review of these areas is necessary, and subsequent imaging will be required in cases with suspicious features.

Scrutiny of the skin, muscles and subcutaneous fat that has been covered by the imaging field-of-view is also required. Occasionally, metastases to these regions can aid the identification and staging of malignancy. 


\section{Breasts}

Breast cancer is one of the most common forms of cancer in females [43], and it is inevitable therefore that breast cancers will be identified incidentally on cardiac imaging. Features such as spiculation, distortion of the adjacent breast tissue and an irregular contour can help to identify malignant lesions. However, the predictive value of non-dedicated CT to identify breast malignancy is low [44]. Therefore, if suspicious lesions are identified, further review by the breast team with mammography or ultrasound should be considered. In addition to malignant INCF in the breast, several benign breast lesions are common including fibroadenoma, fat necrosis and breast cysts.

\section{Economic implications and psychological impact}

The burden of further investigations, management and follow-up contributes to the cost and psychological impact of INCF.

The cost of INCF depends on the prevalence of abnormal findings, follow-up imaging practices and local costs. A Danish study in 2011 of 1383 patients undergoing coronary CT incurred a cost of 58 euros per patient for the assessment of INCF [45]. A smaller study in 2008 in the USA of 151 patients found a cost of $\$ 17.42$ per patient for follow-up imaging, not including clinic follow-up [46]. A Canadian study which also considered costs from investigations such as lung biopsies and the associated complications found a much higher cost per patient of $\$ 59.62$ per patient [47]. An Australia study identified a cost per patient of $\$ 63.62$ to perform additional imaging for lung nodules [17]. In patients undergoing investigation prior to TAVI, the cost to followup INCF was low at $£ 32.69$ per TAVI patient (ED).

When contextualised per individual, the cost does not seem significant, but it is important to consider these costs with reference to clinical benefits and the number of cardiac imaging investigations which are now being performed. A Danish study found that the cost of INCF equated to 40,190 euros to save one life from malignancy [45]. Goehler et al. estimated that the cost per quality adjust life year for lung nodule followup was $\$ 154,000$, which is greater than the normal accepted level from an intervention [48]. However, when considering these results, it is important to note that they were carried out prior to the updated Fleischner guidelines which reduce the number of nodules which require follow-up (Table 2). Indeed, application of these new guidelines would reduce the cost of lung nodule follow-up by $57 \%$, from $£ 7.04$ to $£ 3$ per patient, by reducing the number of patients requiring follow-up. Further studies have demonstrated a 56\% reduction in follow-up of pulmonary nodules when using the new Fleischner guidelines [49•].

Whether or not INCF lead to further follow-up is impacted by a variety of parameters related to both physicians and patients [50]. In the past, it was suggested that INCF could be ignored and only the cardiac findings reported [51]. However, current opinion is that that all imaged organs should be assessed, as to ignore INCF would deny the patient the ability to share decision making and access potential treatment. The identification of INCF may benefit patients by identifying previously un-diagnosed conditions which can be treated. However, they may also cause anxiety and the burden of further follow-up investigations, clinic consultations and treatments [52]. Nevertheless, studies have shown that patients value the opportunity to know about incidental imaging findings [53]. Good communication is important in minimising the potential distress caused by the identification of INCF [54].

\section{Conclusion}

INCF are common in cardiac imaging and can occur within multiple anatomical areas. The wide range of INCF which can be identified illustrates the depth of knowledge and experience required to identify and interpret these findings. While many INCF are benign, an important proportion require further investigation, follow-up or treatment. Questions have been raised regarding the cost effectiveness and clinical implications of investigating INCF; however, new guidance for the management of 
pulmonary nodules will reduce the requirement for follow-up imaging and improve cost effectiveness. It is important that all images are reviewed for potentially clinically significant INCF, as important treatable diseases, including malignancy, may be identified.

\section{Compliance with Ethical Standards}

Conflict of Interest

Mark T. Macmillan declares no potential conflicts of interest.

Michelle C. Williams is a consultant for GE Healthcare.

Human and Animal Rights and Informed Consent

This article does not contain any studies with human or animal subjects performed by any of the authors.

\section{Open Access}

This article is distributed under the terms of the Creative Commons Attribution 4.0 International License (http://creativecommons.org/licenses/by/4.0/), which permits unrestricted use, distribution, and reproduction in any medium, provided you give appropriate credit to the original author(s) and the source, provide a link to the Creative Commons license, and indicate if changes were made.

\section{References and Recommended Reading}

Papers of particular interest, published recently, have been highlighted as:

- Of importance

- Of major importance

1. O'Sullivan JW, Muntinga T, Grigg S, Ioannidis JPA Prevalence and outcomes of incidental imaging findings: umbrella review. Bmj 2018;361:k2387. Doi: https://doi.org/10.1136/bmj.k2387.

2. Williams MC, Hunter A, Shah ASV, et al. Impact of noncardiac findings in patients undergoing CT coronary angiography: a substudy of the Scottish computed tomography of the heart (SCOT-HEART) trial. Eur Radiol. 2018;70(6):ii1-8. https://doi.org/10.1007/ s00330-017-5181-5

This study analysed the incidental findings identified in patients undergoing CCTA for suspected angina as part of the SCOT-HEART study. The findings indicated that application of the new Fleischner or British Thoracic Society guidelines significantly reduced the cost follow-up of incidenta pulmonary nodules.

3.• Flor N, Di Leo G, Squarza SAC, et al. Malignant incidental extracardiac findings on cardiac CT: systematic review and meta-analysis. Am J Roentgenol. 2013;201(3):55564. https://doi.org/10.2214/AJR.12.10306
Systematic review and meta-analysis which considered 19 studies in which patients had undergone any form of cardiac CT and INCF had been reported. Accurate estimates of the prevalence of INCF, clinically significant INCF and malignant INCF were produced.

4. Dunet V, Schwitter J, Meuli R, Beigelman-Aubry C. Incidental extracardiac findings on cardiac MR: systematic review and meta-analysis. J Magn Reson Imaging. 2016;43(4):929-39. https://doi.org/10.1002/ jmri.25053.

5. Zadro C, Roussel N, Cassol E, Pascal P, Petermann A, Meyrignac O, et al. Prognostic impact of myocardial perfusion single photon emission computed tomography in patients with major extracardiac findings by computed tomography for attenuation correction. J Nucl Cardiol. 2017;12(Suppl 1):676-10. https://doi.org/10. 1007/s12350-017-0842-y.

6. Irwin RB, Newton T, Peebles C, Borg A, Clark D, Miller $\mathrm{C}$, et al. Incidental extra-cardiac findings on clinical 
CMR. Eur Heart J Cardiov Imaging. 2013;14(2):15866. https://doi.org/10.1093/ehjci/jes133.

7. McKenna DA, Laxpati M, Colletti PM. The prevalence of incidental findings at cardiac MRI. Open Cardiovasc Med J. 2008;2(1):20-5. https://doi.org/10.2174/ 1874192400802010020.

8. Buckens CF, Verkooijen HM, Gondrie MJ, Jairam P, Mali WP, van der Graaf Y. Unrequested findings on cardiac computed tomography: looking beyond the heart. PLoS One. 2012;7(4):e32184. https://doi.org/ 10.1371/journal.pone.0032184.

9.• Karius P, Schuetz GM, Schlattmann P, Dewey M. Extracardiac findings on coronary CT angiography: a systematic review. J Cardiovasc Comput Tomogr. 2014;8(3):174-82.e1-6. https://doi.org/10.1016/j. jcct.2014.04.002

This systematic review and meta-analysis of INCF considered 13 studies in which patients had undergone CCTA and was able to give accurate estimates of the prevalence of INCF. Further to this the authors performed subgroup analysis and estimated the prevalence of non-significant, clinically significant, acutely life threating and malignant INCF.

10. Hlatky MA, Iribarren C. The dilemma of incidental findings on cardiac computed tomography editorials published in the journal of the American College of Cardiology reflect the views of the authors and do not necessarily represent the views of JACC or the American College of Cardiology. J Am Coll Cardiol. 2009;54(16):1542-3. https://doi.org/10.1016/j.jacc. 2009.06.024.

11. Delaney FT, Fong KM, Lee JC. Primary thoracic cancers incidentally detected on CT attenuation correction images during myocardial perfusion scintigraphy. Clin Lung Cancer. 2018;19:e575-9. https://doi.org/10. 1016/j.cllc.2018.03.018.

12. Killeen RP, Dodd JD, Cury RC. Noncardiac findings on cardiac CT part I: pros and cons. J Cardiovasc Comput Tomogr. 2009;3(5):293-9. https://doi.org/10.1016/j. jcct.2009.05.003.

13. Staab W, Bergau L, Lotz J, Sohns C. Prevalence of noncardiac findings in computed tomography angiography before transcatheter aortic valve replacement. J Cardiovasc Comput Tomogr. 2014;8(3):222-9. https://doi.org/10.1016/j.jcct.2014.03.004.

14. Lindsay AC, Sriharan M, Lazoura O, Sau A, Roughton $\mathrm{M}$, Jabbour RJ, et al. Clinical and economic consequences of non-cardiac incidental findings detected on cardiovascular computed tomography performed prior to transcatheter aortic valve implantation (TAVI). Int J Cardiovasc Imaging. 2015;31(7):1435-46. https://doi. org/10.1007/s10554-015-0685-Z.

15. Showkathali R, Sen A, Brickham B, Dworakowski R, Wendler O, MacCarthy P. "Incidental findings" during TAVI work-up: more than just an inconvenience. EuroIntervention. 2015;11(4):465-9. https://doi.org/ 10.4244/EIJY14M06_04.

16. Stachon P, Kaier K, Milde S, Pache G, Sorg S, Siepe M, et al. Two-year survival of patients screened for transcatheter aortic valve replacement with potentially malignant incidental findings in initial body computed tomography. Eur Heart J Cardiov Imaging. 2015;16(7):731-7. https://doi.org/10.1093/ehjci/jev055.

17. Robertson J, Nicholls S, Bardin P, Ptasznik R, Steinfort D, Miller A Incidental pulmonary nodules are common on CT coronary angiogram and have a significant cost impact. Heart, Lung and Circulation 2017. Doi: https://doi.org/10.1016/j.hlc.2017. 11.004

18. Fantauzzi J, MacArthur A, Lu M, Jeudy J, White CS Quantitative assessment of percentage of lung parenchyma visualized on cardiac computed tomographic angiography. J Comput Assist Tomogr 2010;34(3):385-387. Doi: https://doi.org/10.1097/ RCT.0b013e3181ce07d3.

19. Northam M, Koonce J, Ravenel JG Pulmonary nodules detected at cardiac CT: comparison of images in limited and full fields of view. Am J Roentgenol 2008;191(3):878-881. Doi: https://doi.org/10.2214/ AJR.07.2939.

20. Muzaffar R, Raslan O, Ahmed F, Goldfarb L, Sterkel B, Osman MM Incidental findings on myocardial perfusion SPECT images. J Nuclear Med Technol 2017;45(3):175-180. Doi: https://doi.org/10.2967/ jnmt.117.195487.

21. Gedik GK, Ergün EL, Aslan M, Caner B. Unusual extracardiac findings detected on myocardial perfusion single photon emission computed tomography studies with Tc-99m sestamibi. Clin Nucl Med. 2007;32(12):920-6. https://doi.org/10.1097/RLU. ob013e318159661b.

22. Sohns JM, Menke J, Schwarz A, Bergau L, Kowallick JT, Schuster A, et al. Incidental findings in cardiac magnetic resonance imaging: superiority of bSSFP over T1w-HASTE for extra-cardiac findings assessment. Int J Cardiovasc Imaging. 2017;33(10):1581-7. https://doi. org/10.1007/s10554-017-1145-8.

23. MacMahon $\mathrm{H}$, Naidich DP, Goo JM, Lee KS, Leung ANC, Mayo JR, et al. Guidelines for management of incidental pulmonary nodules detected on CT images: from the Fleischner society. Radiology. 2017;2017:228-43. https://doi.org/10.1148/radiol. 2017161659

24. Callister MEJ, Baldwin DR, Akram AR, et al. British Thoracic Society guidelines for the investigation and management of pulmonary nodules. Thorax. 2015:ii1-ii54. https://doi.org/10.1136/thoraxjnl2015-207168.

25. MacMahon H, Austin JHM, Gamsu G, Herold CJ, Jett JR, Naidich DP, et al. Guidelines for management of small pulmonary nodules detected on CT scans: a statement from the Fleischner society. Radiology. 2005;237(2):395-400. https://doi.org/10.1148/ radiol.2372041887.

26. Travis WD, Brambilla E, Noguchi M, Nicholson AG, Geisinger K, Yatabe Y, et al. International Association for the Study of Lung Cancer/American Thoracic Society/European Respiratory Society: international multidisciplinary classification of lung 
adenocarcinoma: executive summary. Am Thorac Soc. 2011;8:381-5.

27. National Lung Screening Trial Research Team, Aberle DR, Adams AM, et al. Reduced lung-cancer mortality with low-dose computed tomographic screening. N Engl J Med. 2011;365(5):395-409. https://doi.org/10. 1056/NEJMoa1102873.

28. Field JK, Duffy SW, Baldwin DR, Whynes DK, Devaraj A, Brain KE, et al. UK lung Cancer RCT pilot screening trial: baseline findings from the screening arm provide evidence for the potential implementation of lung cancer screening. Thorax. 2016;71(2):161-70. https:// doi.org/10.1136/thoraxjnl-2015-207140.

29. National Lung Screening Trial Research Team, Church TR, Black WC, et al. Results of initial low-dose computed tomographic screening for lung cancer. N Engl J Med. 2013;368(21):1980-91. https://doi.org/10. 1056/NEJMoa1209120.

30. Williams MC, Murchison JT, Edwards LD, Agustí A, Bakke P, Calverley PMA, et al. Coronary artery calcification is increased in patients with COPD and associated with increased morbidity and mortality. Thorax. 2014;69(8):718-23. https://doi.org/10.1136/ thoraxjnl-2012-203151.

31. Sokolowski FC, Karius P, Rodríguez A, Lembcke A, Wagner M, Hamm B, et al. Extracardiac findings at cardiac MR imaging: a single-Centre retrospective study over 14 years. Eur Radiol. 2018;27(Suppl 1):1640-9. https://doi.org/10.1007/s00330-018-5432-0.

32. Ingram CE, Belli AM, Lewars MD, Reznek RH. Husband JE Normal lymph node size in the mediastinum: a retrospective study in two patient groups. Clin Radiol. 1989;40(1):35-9.

33. Ziyade S, Pinarbasili NB, Ziyade N, Akdemir OC, Sahin F, Soysal Ö, et al. Determination of standard number, size and weight of mediastinal lymph nodes in postmortem examinations: reflection on lung cancer surgery. J Cardiothorac Surg. 2013;8(1):94. https://doi. org/10.1186/1749-8090-8-94.

34. Callen PW, Korobkin M. Isherwood I computed tomographic evaluation of the retrocrural prevertebral space. AJR Am J Roentgenol. 1977;129(5):907-10. https://doi.org/10.2214/ajr.129.5.907.

35. Budoff MJ, Nasir K, Katz R, Takasu J, Carr JJ, Wong ND, et al. Thoracic aortic calcification and coronary heart disease events: the multi-ethnic study of atherosclerosis (MESA). Atherosclerosis. 2011;215(1):196-202. https://doi.org/10.1016/j.atherosclerosis.2010.11.017.

36. Burris AC, Boura JA, Raff GL. Chinnaiyan KM triple rule out versus coronary CT angiography in patients with acute chest pain: results from the ACIC consortium. JACC Cardiovasc Imaging. 2015;8(7):817-25. https:// doi.org/10.1016/j.jcmg.2015.02.023.

37. Greulich S, Backes M, Schumm J, Grün S, Steubing H, Sechtem U, et al. Extra cardiac findings in cardiovascular MR: why cardiologists and radiologists should read together. Int J Cardiovasc Imaging. 2014;30(3):609-17. https://doi.org/10.1007/s10554014-0368-1.
38. Haugen BR, Alexander EK, Bible KC, Doherty GM, Mandel SJ, Nikiforov YE, et al. American Thyroid Association management guidelines for adult patients with thyroid nodules and differentiated thyroid Cancer: the American Thyroid Association guidelines task force on thyroid nodules and differentiated thyroid Cancer. Thyroid. 2015;2016:1-133. https://doi.org/10. 1089/thy.2015.0020.

39. Grady AT, Sosa JA, Tanpitukpongse TP, Choudhury KR, Gupta RT. Hoang JK radiology reports for incidental thyroid nodules on CT and MRI: high variability across subspecialties. Am J Neuroradiol. 2015;36(2):397402. https://doi.org/10.3174/ajnr.A4089.

40. Bosniak MA. The current radiological approach to renal cysts. Radiology. 1986;158(1):1-10. https://doi.org/ 10.1148/radiology.158.1.3510019.

41. Israel GM, Bosniak MA. an update of the Bosniak renal cyst classification system. Urology. 2005;66(3):484-8. https://doi.org/10.1016/j.urology.2005.04.003.

42. European Study Group on Cystic Tumours of the Pancreas European evidence-based guidelines on pancreatic cystic neoplasms. European evidence-based guidelines on pancreatic cystic neoplasms. Gut. 2018;67:789-804. https://doi.org/10.1136/gutjnl2018-316027.

43. Torre LA, Bray F, Siegel RL, Ferlay J, Lortet-Tieulent J. Jemal a global cancer statistics, 2012. CA Cancer J Clin. 2015;65(2):87-108. https://doi.org/10.3322/caac. 21262.

44. Moyle P, Sonoda L, Britton P. Sinnatamby R incidental breast lesions detected on CT: what is their significance? Br J Radiol. 2010;83(987):233-40. https://doi. org/10.1259/bjr/58729988.

45. Bendix K, Jensen JM, Poulsen S, Mygind N. Nørgaard BL coronary dual source multi detector computed tomography in patients suspected of coronary artery disease: prevalence of incidental extra-cardiac findings. Eur J Radiol. 2011;80(1):109-14. https://doi.org/10. 1016/j.ejrad.2010.05.024.

46. Lee CI, Tsai EB, Sigal BM, Plevritis SK, Garber AM. Rubin GD incidental Extracardiac findings at coronary CT: clinical and economic impact. Am J Roentgenol. 2010;194(6):1531-8. https://doi.org/10.2214/AJR.09. 3587.

47. MacHaalany J, Yam Y, Ruddy TD, Abraham A, Chen L, Beanlands RS, et al. Potential clinical and economic consequences of noncardiac incidental findings on cardiac computed tomography. Jacc. 2009;54(16):1533-41. https://doi.org/10.1016/j.jacc. 2009.06.026.

48. Goehler A, McMahon PM, Lumish HS, et al. Costeffectiveness of follow-up of pulmonary nodules incidentally detected on cardiac computed tomographic angiography in patients with suspected coronary artery disease. Circulation. 2014;130(8):668-75. https://doi. org/10.1161/CIRCULATIONAHA.113.007306.

49. Scholtz J-E, Lu MT, Hedgire S, et al. Incidental pulmonary nodules in emergent coronary CT angiography for suspected acute coronary syndrome: impact of revised 
2017 Fleischner Society Guidelines. J Cardiovasc Comput Tomogr. 2017;12(1):28-33. https://doi.org/ 10.1016/j.jcct.2017.11.005

This study identified a 56\% reduction in follow-up of pulmonary nodules when applying the new Fleischner society guidelines in patients undergoing CCTA for acute coronary syndrome.

50. Zafar HM, Bugos EK, Langlotz CP. Frasso R "chasing a ghost": factors that influence primary care physicians to follow up on incidental imaging findings. Radiology. 2016;281(2):567-73. https://doi.org/10.1148/radiol. 2016152188.

51. Budoff MJ, Gopal A. Incidental findings on cardiac computed tomography. Should we look? J Cardiovasc Comput Tomogr. 2007;1(2):97-105. https://doi.org/ 10.1016/j.jcct.2007.04.002.

52. Schmidt CO, Hegenscheid K, Erdmann P, Kohlmann T, Langanke M, Völzke H, et al. Psychosocial consequences and severity of disclosed incidental findings from whole-body MRI in a general population study. Eur Radiol. 2013;23(5):1343-51. https://doi. org/10.1007/s00330-012-2723-8.

53. Devcich DA, Ellis CJ, Waltham N, Broadbent E. Petrie KJ seeing what"s happening on the inside: patients" views of the value of diagnostic cardiac computed tomography angiography. Br J Health Psychol. 2014;19(4):810-22. https://doi.org/10.1111/bjhp. 12080.

54. Freiman MR, Clark JA, Slatore CG, Gould MK, Woloshin S, Schwartz LM, et al. Patients' knowledge, beliefs, and distress associated with detection and evaluation of incidental pulmonary nodules for cancer: results from a multicenter survey. J Thorac Oncol. 2016;11(5):700-8. https://doi.org/10.1016/j.jtho. 2016.01.018. 